\title{
Facile Preparation of Copper and Tin Oxide Nanoparticles as Efficient Adsorbent of Heavy Metals from Wastewater
}

\author{
Ahmed Elsayed Abdelaal ${ }^{1}$, Mohamed Abdel-Motaleb ${ }^{1}$, Marwa Farouk El Kady ${ }^{2,3}$, \\ Abdel-Rahman Mustafa Hamed ${ }^{1}$ \\ ${ }^{1}$ Faculty of Science, Al-Azhar University (Assuit Branch), Assuit, Egypt \\ ${ }^{2}$ Chemical and Petrochemical Engineering Department, Egypt-Japan University of Science and Technology, Alexandria, Egypt \\ ${ }^{3}$ Advanced Technology and New Materials Research Institute (ATNMRI), City for Scientific Research and Technological Applications \\ (SRTA-City), Alexandria, Egypt
}

Email address:

Chemist_ahmed2071986@yahoo.com (A. E. Abdelaal)

\section{To cite this article:}

Ahmed Elsayed Abdelaal, Mohamed Abdel-Motaleb, Marwa Farouk El Kady, Abdel-Rahman Mustafa Hamed. Facile Preparation of Copper and Tin Oxide Nanoparticles as Efficient Adsorbent of Heavy Metals from Wastewater. International Journal of Ecotoxicology and Ecobiology. Vol. 6, No. 1, 2021, pp. 1-7. doi: 10.11648/j.ijee.20210601.12

Received: February 2, 2021; Accepted: February 19, 2021; Published: March 9, 2021

\begin{abstract}
Heavy metal removal from waste water is essential to solve the global water crises. Transition metal oxide nanoparticles are promising candidates for these applications. Herein, Copper oxide and Tin oxide nanoparticles have been prepared via Facile and economic perception method starting from commercial precursors. The obtained nanoparticles were in flack-like shape and spherical shape for Copper oxide and Tin oxide nanoparticles, respectively. All prepared nanoparticles are in crystalline phases, where the prepared Copper oxide and Tin oxide nanoparticles were in monoclinic and tetragonal crystalline phases, respectively. The crystal size of Copper oxide and Tin oxide nanoparticles were $12 \mathrm{~nm}$ and $13 \mathrm{~nm}$ respectively. $\mathrm{Cd}$ and $\mathrm{Pb}$ ions were removed from wastewater by the obtained Copper oxide and Tin oxide nanoparticles. The adsorption processes were studied under various parameters, such as; contact time and $\mathrm{pH}$ values. The highest removal uptake was about $\sim 99 \%$ of $\mathrm{Pb}$ ions were recorded for Copper oxide nanoparticles. This uptake process carried out after $30 \mathrm{~min}$ in a neutral medium (pH 7). While, Tin oxide nanoparticles removed about $\sim 94 \%$ at the same conditions. On the other hand, Copper oxide nanoparticles removed about $\sim 57 \%$ from Cd ions. This uptake process carried out after $30 \mathrm{~min}$ in a partially acidic medium (pH 6). While, Tin oxide nanoparticles removed about $\sim 54 \%$ at the same conditions. Finally, it is highly recommended to use Copper oxide and Tin oxide nanoparticles as promising adsorbents for heavy metal removal applications.
\end{abstract}

Keywords: Copper Oxide Nanoparticles, Tin Oxide Nanoparticles, Heavy Metal Removal

\section{Introduction}

Water is the most essential resource for all types of life on earth. So, the availability of clean and affordable water is considered as the the most basic humanitarian goals, and remains a global basic challenge.

The current water supplies face massive challenges. Therefore, it is critical to apply a basic water treatment in the affected areas. Generally, human activities play a greater role in exacerbating water scarcity by contaminating natural water sources [1].

Industrial wastewater considered as one of the main pollution sources of water. Most of industrial wastewater was discharged into natural water sources, such as; rivers, lakes and coastal areas. These caused serious pollution problems in the water environment, and therefore, grate negative effects to the eco-system and human's life. The industrial wastewater contains significant quantities of heavy metals, such as; copper, cadmium, zinc, silver, lead, chromium, nickel, vanadium, platinum, and titanium. Heavy metals-contaminated is produced from different industries, such as; anodizing-cleaning, electroplating, electro less depositions, milling, conversion-coating, and etching [2, 3].

Since, heavy metals considered as non-biodegradable and potentially toxic elements. They cannot be degraded or destroyed naturally unlike organic pollutants therefore persist in our environment so pose a different kind of challenge for 
remediation [4].

Heavy metals are dangerous especially when they contaminate the aquatic ecosystem, the main source of heavy metals may be industrial or consumer wastes releasing heavy metals into rivers, streams, lakes, and groundwater [5].

Heavy metals pollutants cause serious health deceases, including reduced growth and development, cancer, organ damage, liver damage, nervous system damage, anemia, diarrhea, insomnia, nausea, Wilson's disease, gastrointestinal (GI) disorders, stomatitis, tremor, ataxia, paralysis, vomiting and convulsion, depression and death. Exposures to some even small dose of heavy metals, such as; lead and mercury may consider as a reason of autoimmunity development, where a human's immune system attacks its own cells. This phenomena cause various diseases, such as; kidney diseases, and rheumatoid arthritis. Children may receive higher doses of these heavy metals than adults, since they consume more food for their growth than adults [6].

In recent years, several techniques for the removal of heavy metals from the wastewater are development such as Chemical precipitation [7, 8], ion- exchange [9], reverse osmosis [10], and adsorption [6, 11].

There are many recent studies indicating that many of the nano metal oxides show a very favorable absorption of heavy metals in terms of high capacitance and selectivity, which may lead to deep removal of toxic metals to meet increasingly stringent regulations. They are considered as a promising adsorbent for water treatment applications due to their enormous surface area which could be increased by using various functionalized groups.

Metal oxides nanoparticles are effective, economic adsorbents for various pollutants, such as; dyes and heavy metals. The adsorption process is mainly controlled by complexation between ion pollutant and the oxygen in metal oxides [12].

Metal oxide nanoparticles could be used in various applications such as gas sensors, solar energy conversions biomedical, adsorbents, catalysis, pharmaceutical products, semiconductors, surface coatings, and in the medical.

Metal oxides nanoparticles demonstrate high removal efficiency of heavy metal from wastewater, due to their high surface area and much more surface active sites comparing to bulk materials [13].

Regarding to heavy metal pollutions, there has been a rising interest recently for the development of materials capable of removing these pollutants. Currently, metal oxides nanoparticles, such as; zinc oxide, ferric oxides, copper oxide, manganese oxides, magnesium oxides aluminum oxides, titanium oxides, and cerium oxides are identified as promising adsorbents for heavy metal removal from aqueous systems $[14,15]$.

Among all metal oxide nanoparticles we will focused $\mathrm{CuO}$, $\mathrm{SnO}_{2}$, where CuO-NPs attracts attention because of its large surface area, enhanced oxygen adsorption capability. Due to its high surface these nanoparticles are considered as promising candidate with enhanced photocatalytic activity [16]. The copper oxide nanoparticles (CuO-NPs) possess a wide range of applications, using in removal of dyes [17], gas sensors [18], solar energy transformation [19], and remove heavy metals [20].

Tin oxide $\left(\mathrm{SnO}_{2}\right)$ is consider one of the most nanoparticles to be inspected recently; $\mathrm{SnO}_{2}$ nanoparticles is a n-type semiconductor, which could be used in various applications such as in solid-state gas sensors [21], transparent conducting electrodes [22], rechargeable Li batteries [23, 24], and optical electronic devices [25], and as pollutant adsorbent, such as; heavy metal ions and dyes [26, 27], however the available literature on adsorption of heavy metal ions by Tin oxide nanoparticles is limited.

The current research aims to study the effect of nano copper oxide and tin oxide nanoparticles as adsorbent for lead and cadmium from wastewater. Hence, this study aims to study the adsorption behavior of lead and cadmium ions from water using the synthesized $\mathrm{CuO}$ and $\mathrm{SnO}_{2}$ nanoparticles under different operating conditions to determine the optimum conditions for $\mathrm{Pb}$ and $\mathrm{Cd}$ removal. So, in order to determine the optimum condition for removing lead and cadmium from solution, adsorption studies were performed by evaluating various parameters, such as: $\mathrm{pH}$, contact time, and initial concentration of lead and cadmium, adsorbent doses.

\section{Materials and Methods}

\subsection{Chemicals and Reagents}

The chemicals used in the experiment are analytic reagent grade. Copper(II) nitrate trihydrate $\mathrm{Cu}\left(\mathrm{NO}_{3}\right)_{2} \cdot 3 \mathrm{H}_{2} \mathrm{O}(98 \%)$ (Sigma-Aldrich), poly ethylene glycol (PEG) (Mwt 10000) (PANREAC, Spain), Tin (11) Chloride dehydrate $\mathrm{SnCl}_{2} \cdot 2 \mathrm{H}_{2} \mathrm{O}$ (98\%-101\%) (Merck), Ethylene glycol, Ammonium hydroxide solution $\mathrm{NH}_{3} \mathrm{OH}$ (25\%) (Sigma Aldrich, Germany), Lead (11) Nitrate $\mathrm{Pb}\left(\mathrm{NO}_{3}\right)_{2}$ (99.9\%) (Wako), Cadmium Chloride 2.5-Hydrate (99.9\%) (Wako), sodium hydroxide $(\mathrm{NaOH})$ (Extra pure) (Oxford), hydrochloric acid ( $\mathrm{HCl})(37 \%)$ (Fisher Scientific).

In all experiments double water distilled water was used, prepared and diluted and used to wash all glass.

\subsection{Copper Oxide Nano-particle Preparation}

Copper oxide Nano-particles were been prepared as following; $0.725 \mathrm{~g}$ of $\mathrm{Cu}\left(\mathrm{NO}_{3}\right)_{2} \cdot 3 \mathrm{H}_{2} \mathrm{O}$ was dissolved in $50 \mathrm{ml}$ of PEG (poly ethylene glycol) was added into the solution. Then, sodium hydroxide $(\mathrm{NaOH})$ added during stirred until the $\mathrm{pH}$ 11. During that, the mixture was heated in the microwave oven radiation with power $900 \mathrm{~W}$ for 1.45 minutes until complete dryness of the mixture then the precipitates were filtered and then washed by distilled water. The precipitate was dried in an oven for three hours at $75^{\circ} \mathrm{C}$.

\subsection{Tin Oxide $\left(\mathrm{SnO}_{2}\right)$ Nano-particle Preparation}

Tin Oxide $\left(\mathrm{SnO}_{2}\right)$ Nano-particle were been prepared as following; $50 \mathrm{ml}(0.1)$ of $\mathrm{SnCl}_{2} .2 \mathrm{H}_{2} \mathrm{O}$ mixed with $10 \mathrm{ml}$ of Ethylene glycol. Then added, Ammonium hydroxide solution $\left(\mathrm{NH}_{3} \mathrm{OH}\right)$, during stirred until the $\mathrm{pH}$ 8. During the mixing 
process the mixture was heated in the microwave oven radiation with power $900 \mathrm{~W}$ for 3 minutes until complete dryness of the mixture then the precipitates were filtered and then washed by distilled water. The precipitate was dried in an oven for three hours at $75^{\circ} \mathrm{C}$.

\subsection{Adsorption Procedure}

The adsorption experiments of (Cadmium or Lead) removal from the polluted waste water using synthesized nanoparticle (Copper oxide or Tine oxide) as adsorbent materials.

The adsorption test was performed according to the following methodology:

Batch adsorption experiments were carried out at room temperature by shaking solution flasks at $150 \mathrm{rpm}$ containing fixed dose of adsorbent $(0.1 \mathrm{~g}-0.4 \mathrm{~g})$ of (nanoparticle Copper oxide or Tine oxide) in (50) $\mathrm{ml}$ a predetermined concentration (25ppm-100ppm) of Cadmium or Lead metal solution during certain time and various $\mathrm{pH}$ (3-11) Experiments were carried out at initial $\mathrm{pH}$ value 7 for cadmium and 6 for lead. After finishing the mixing time intervals the adsorbent materials were separated from waste water contain (cadmium or lead) heavy metal by Centrifuge. Then the cadmium or lead heavy metal concentrations were determined after and before the treatment process using Inductive Coupling Plasma-Optical Emission Spectroscopy Optima (8300) (ICP-OES). The percentage of ions removal using each adsorbent material separately was determined using the following equation [28]:

$$
\% R=\frac{\mathrm{C}_{\mathrm{o}}-\mathrm{C}_{\mathrm{e}}}{\mathrm{C}_{\mathrm{o}}} \times 100
$$

Where $\mathrm{R}$ is the cadmium or lead removal, $\mathrm{C}_{\mathrm{o}}$ and $\mathrm{C}_{\mathrm{e}}$ are the initial and final concentration of the metal ions in solution, respectively.

In order to calculate the uptake capacity of the metal ion, the up take amounts per gram of prepared adsorbent material was evaluated from the change in solution concentration using the following equation [29]:

$$
Q(m g / g)=\frac{\mathrm{V}\left(\mathrm{C}_{\mathrm{o}}-\mathrm{C}\right)}{\mathrm{M}} \times 100
$$

Where Q is the uptake capacity $(\mathrm{mg} / \mathrm{g}), \mathrm{V}$ is the volume of the solution $(\mathrm{ml})$ and $\mathrm{M}$ is the mass of the solid material $(\mathrm{g})$.

\section{Results and Discussion}

\subsection{Characterization of Adsorbents}

\subsubsection{X-Ray Diffraction Analyses}

Figure 1 shows the XRD patterns of the prepared nanoparticles. The prepared $\mathrm{CuO}$ nanoparticles were highly crystalline than $\mathrm{SnO}_{2}$ nanoparticles. Figure 1-a confirm that $\mathrm{CuO}$ nanoparticles was successfully synthesized by precipitation method using microwave heating technique. It is clearly noticed that the prepared sample are identical to the mono-phase of $\mathrm{CuO}$ with a monoclinic structure (ICDD card No. 048-1548). Figure 1-b confirm that $\mathrm{SnO}_{2}$ nanoparticles was successfully prepared by sol-gel method using microwave heating technique and the diffraction peaks indexed to the tetragonal $\mathrm{SnO}_{2}$ phase (JCPDS Card No. 88-0287).

These results are in a good agreement with those published by other researchers $[30,31]$, as summarized in table 1 .

The crystalline size of the prepared nanoparticles was calculated for XRD data by using Debye Scherer equation [20]:

$$
\mathrm{D}=0.9 \lambda / \beta \operatorname{Cos} \theta
$$

Where $\lambda$ is the $\mathrm{X}$-ray wave length, $\theta$ is the Bragg angle, $\beta$ is the line broadening at half the maximum intensity in radians.

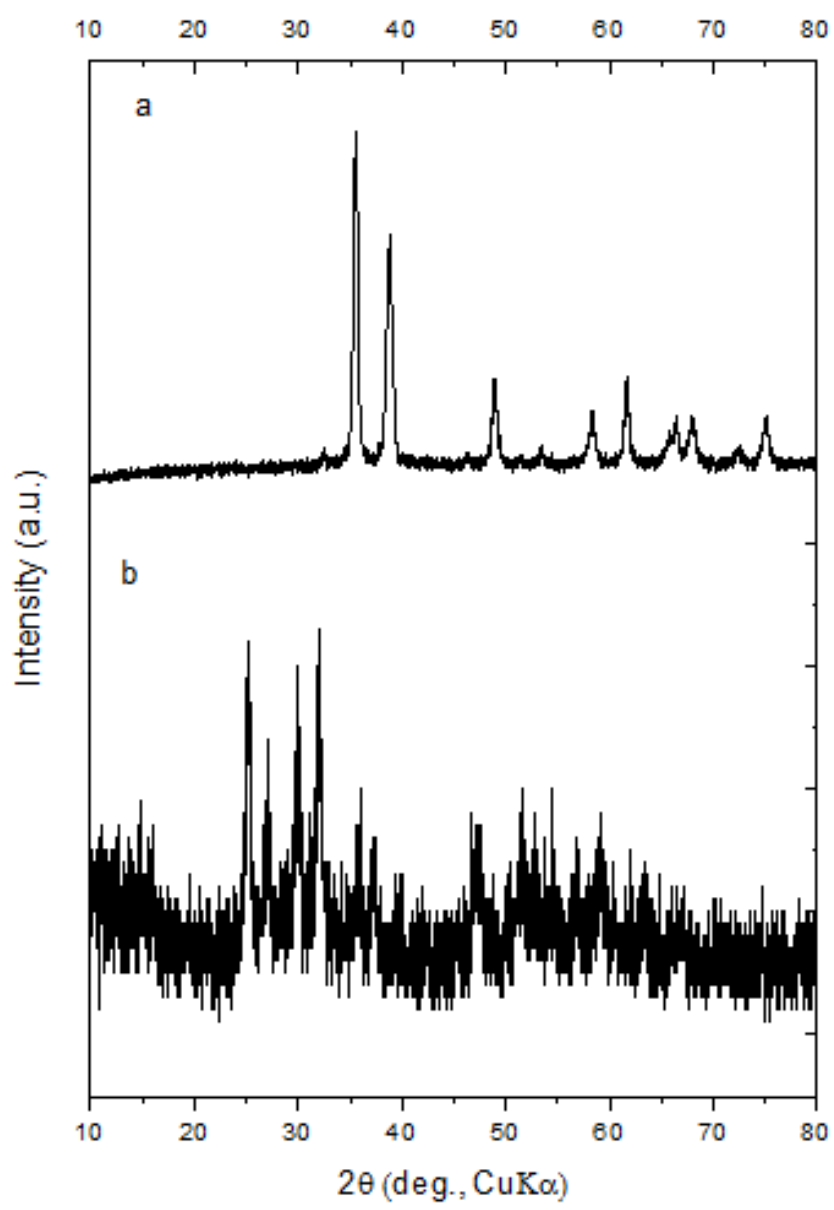

Figure 1. XRD patterns of prepared (a) $\mathrm{CuO}$ and (b) $\mathrm{SnO}_{2}$ nanoparticles.

Table 1 summarizes the structural data of the prepared $\mathrm{CuO}$ and $\mathrm{SnO}_{2}$ nanoparticles comparing to literature survey.

\subsubsection{Scanning Electron Microscopic (SEM) Analyses}

To evaluate the morphology of the prepared nanoparticles, $\mathrm{CuO}$ and $\mathrm{SnO}_{2}$ nanoparticles were characterized by scanning electron microscopy (SEM). Figure 2 shows the SEM micrographs of the prepared nanoparticles. The prepared $\mathrm{CuO}$ nanoparticles were in large flake-like shape figure 2-a, while the prepared $\mathrm{SnO}_{2}$ nanoparticles were in small spherical shape figure 2-b. These findings are in a good agreement with those published by other researchers [30, 31], as summarized in table 1. 


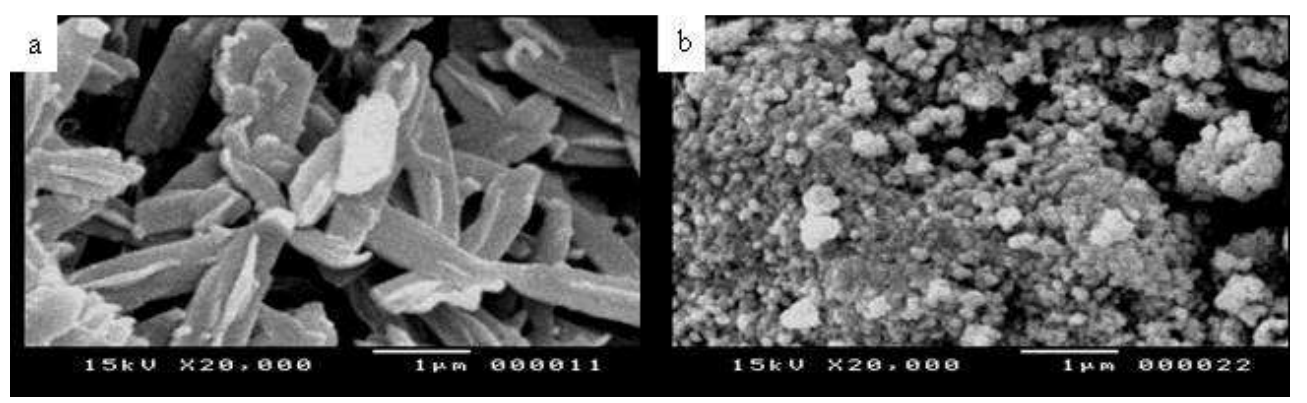

Figure 2. SEM micrographs of the prepared (a) $\mathrm{CuO}$ and (b) $\mathrm{SnO}_{2}$ nanoparticles.

Table 1. The crystalline data of the prepared $\mathrm{CuO}$ and $\mathrm{SnO}_{2}$ nanoparticles comparing to literature survey.

\begin{tabular}{llllll}
\hline Nanoparticles & Crystalline phase & Crystal size (nm) & morphology & application & Reference \\
\hline $\mathrm{CuO}$ & monoclinic & 12 & large flake-like shape & Water treatment & Current work \\
$\mathrm{SnO}_{2}$ & tetragonal & 13 & small spherical & Water treatment & Current work \\
$\mathrm{CuO}$ & monoclinic & 25 & porous balls & N/A & {$[30]$} \\
$\mathrm{SnO}_{2}$ & tetragonal & 10 & spherical & Water treatment & {$[31]$} \\
\hline
\end{tabular}

\subsection{Adsorption Studies of Cadmium and Lead on CuO Nanoparticles}

\subsubsection{Effect of Contact Time}

The removal of heavy metal $(\mathrm{Cd}$ and $\mathrm{Pb})$ from aqueous solution was studied as function of contact time in the range of (0-120) min at (25) ppm initial concentration for both, $\mathrm{pH}$ 7 for $\mathrm{Cd} \mathrm{pH} 6$ for $\mathrm{Pd}$ at room temperature.

Figure 3 shows the effect of contact time on the adsorption of both of $\mathrm{Cd}$ and $\mathrm{Pb}$ using the prepared $\mathrm{CuO}$ nanoparticles as adsorbents. It is noticeable that, the adsorption of $\mathrm{Pb}$ is higher than $\mathrm{Cd}$ for $\mathrm{CuO}$ nanoparticles, Cadmium and Lead ions were rapidly removed by $\mathrm{CuO}$ nanoparticles (at 30 mints).

The adsorption rate could be classified into two main stages. In the first stages, the adsorption efficiency of the pollutants ion by the $\mathrm{CuO}$ nanoparticles increased rapidly due to the abundant availability of active binding sites on the $\mathrm{CuO}$ nanoparticles, and with gradual occupancy of these sites, the adsorption efficiency decreased in the last stages [32]. That means that the equilibrium status can be achieved after 30 minutes for both.
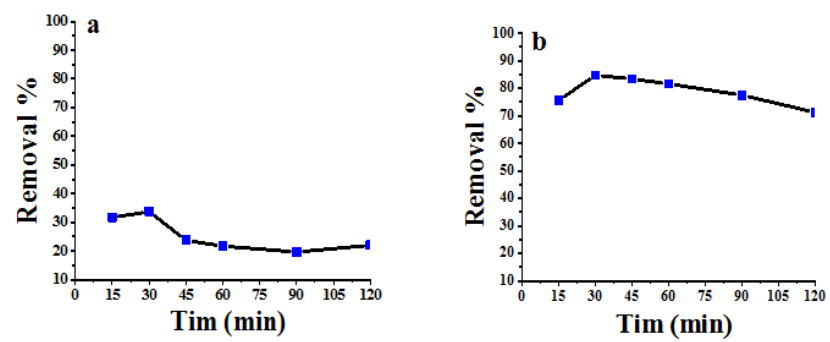

Figure 3. Graphical representation which shows the effect of contact time on the adsorption of (a) Cd@CuO (b) Pb@CuO. at adsorbentweight=0.1g, 25 ppm initial concentration for both, $\mathrm{pH} 7$ for $\mathrm{Cd} \mathrm{pH} 6$ for $\mathrm{Pd}$, at room temperature.

\subsubsection{Effect of $\mathrm{pH}$ Values}

The creation of adsorbed sites depends mainly on the value of solution $\mathrm{pH}$. Where, the active sites on the surface of adsorbent can either be protonated or deprotonated with hydrogen and hydroxide ions. By other words, the surface charge of the adsorbent may be influenced by different values of solution $\mathrm{pH}$ [33].

Removal of $(\mathrm{Cd}$ and $\mathrm{Pb})$ from aqueous solution was studied as function of $\mathrm{pH}$ in the range of (3-11) at (25) ppm concentration, contact time $30 \mathrm{mint}$, at room temperature. Figure 4 shows the effect of $\mathrm{pH}$ values on the adsorption of both of $\mathrm{Cd}$ and $\mathrm{Pb}$ using the prepared $\mathrm{CuO}$ nanoparticles as adsorbents. It is noticeable that, the highest adsorption values were recorded at alkaline media. On the other hands, hydrogen ion concentration ( $\mathrm{pH}$ value) is considered as the main important parameters that affect the adsorption process of pollutants ions from wastewater. This is may be due to that, the solubility of the metal ions is mainly affected by the solution $\mathrm{pH}$ value. In addition to, hydrogen ion concentration may substitute some positive ions found in the active sites and impact the degree of ionization of the adsorbate during the reaction [34].
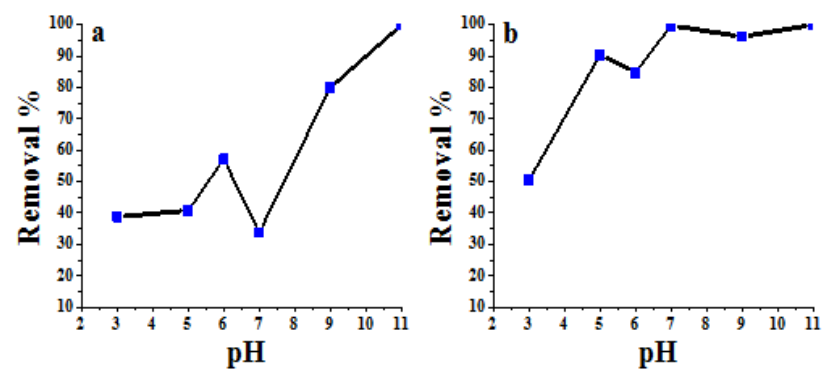

Figure 4. Graphical representation which shows the effect of $p H$ values on the adsorption of (a) Cd@CuO (b) Pb@CuO. at adsorbentweight=0.1g, 25 ppm initial concentration for both, contact time $30 \mathrm{~min}$ for both, at room temperature.

Figure 4-a Show the removal of $\mathrm{Cd}$ ions by $\mathrm{CuO}$ nanoparticles upon the initial $\mathrm{pH}$ on the sorption in range of (3-11). The metal removal from solution at $\mathrm{pH}$ beyond 8 did not provide any accurate results, where the pollutants ions are 
precipitated as hydroxides. Therefore, the removal curve increased due to there was not Cadmium ions to be removed. By other words, the solution seems to be clear because of the metal precipitation [35]. The effect of $\mathrm{pH}$ on the adsorption behavior of nano $\mathrm{CuO}$ for $\mathrm{Cd}$ was shown in Figure 4. The initial $\mathrm{pH}$ of the solution significantly affected the adsorption capacity of the adsorbent, Removal of $\mathrm{Cd}$ ions increases gradually with increasing solution $\mathrm{pH}$ from 3 to 6 . The maximum recorded value was reached at $\mathrm{pH}$ of 6 . So, it was considered as optimum condition. At lower $\mathrm{pH}$ values, the metal ion removal was limited; this is due to the presence of $\mathrm{H}^{+}$ions which compete with the $\mathrm{Cd}$ ions for the adsorption sites.

The effect of initial $\mathrm{pH}$ on the adsorption of $\mathrm{Pb}$ ions onto $\mathrm{CuO}$ nanoparticles was evaluated within the $\mathrm{pH}$ range of (3-11) figure 4-b. Removing metal from solution at $\mathrm{pH}$ beyond 8 did not provide any accurate results, where the pollutants ions are precipitated as hydroxides. Therefore, the removal curve increased due to there was not Lead ions to be removed. By other words, the solution seems to be clear because of the metal precipitation [35]. Figure 4 shows the adsorption behavior of $\mathrm{Pd}$ ions by $\mathrm{CuO}$ nanoparticles upon changing initial solution $\mathrm{pH}$ value. It's clear that the initial solution $\mathrm{pH}$ value has a remarkable effect on the adsorption capacity. Removal of $\mathrm{Pd}$ ions increases gradually with increasing solution $\mathrm{pH}$ from 3 to 7 . The maximum recorded value was reached at $\mathrm{pH}$ of 7 . So, it was considered as optimum condition. At lower $\mathrm{pH}$ values, the metal ion removal was limited; this is due to the presence of $\mathrm{H}^{+}$ions which compete with the Pd ions for the adsorption sites.

\subsection{Adsorption studies of Cadmium and Lead on $\mathrm{SnO}_{2}$ Nanoparticles}

\subsubsection{Effect of Contact Time}

The removal of heavy metal $(\mathrm{Cd}$ and $\mathrm{Pb})$ from aqueous solution was studied as function of contact time in the range of (0-120) min at (25) ppm initial concentration for both, $\mathrm{pH}$ 7 for $\mathrm{Cd} \mathrm{pH} 6$ for $\mathrm{Pd}$ at room temperature.
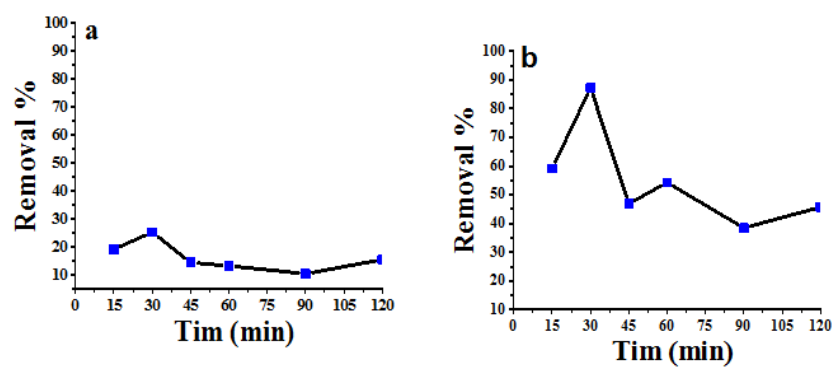

Figure 5. Graphical representation which shows the effect of contact time on the adsorption of (a) Cd@SnO $\mathrm{S}_{2}$ (b) $\mathrm{Pb} @ \mathrm{SnO}_{2}$. at adsorbent weight=0.1g, 25 ppm initial concentration for both, $\mathrm{pH} 7$ for $\mathrm{Cd} \mathrm{pH} 6$ for $\mathrm{Pd}$, at room temperature.

Figure 5 shows the effect of contact time on the adsorption of both of $\mathrm{Cd}$ and $\mathrm{Pb}$ using the prepared $\mathrm{SnO}_{2}$ nanoparticles as adsorbents. It is noticeable that, the adsorption of $\mathrm{Pb}$ is higher than $\mathrm{Cd}$ for $\mathrm{SnO}_{2}$ nanoparticles, Cadmium and Lead was rapidly removed by $\mathrm{SnO}_{2}$ nanoparticles (at 30 mints).
The adsorption rate follow the same sequence described earlier [32]. That means that the equilibrium status can be achieved after 30 minutes for both.

\subsubsection{Effect of $\mathrm{pH}$ Values}

The creation of adsorbed sites depends mainly on the value of solution $\mathrm{pH}$. Where, the active sites on the surface of adsorbent can either be protonated or deprotonated with hydrogen and hydroxide ions. By other words, the surface charge of the adsorbent may be influenced by different values of solution $\mathrm{pH}$ [33].

Removal of $(\mathrm{Cd}$ and $\mathrm{Pb})$ from aqueous solution was studied as function of $\mathrm{pH}$ in the range of (3-11) at (25) ppm concentration, contact time $30 \mathrm{mint}$, at room temperature. Figure 6 shows the effect of $\mathrm{pH}$ values on the adsorption of both of $\mathrm{Cd}$ and $\mathrm{Pb}$ using the prepared $\mathrm{SnO}_{2}$ nanoparticles as adsorbents. It is noticeable that, the highest adsorption values were recorded at alkaline media. On the other hands, hydrogen ion concentration ( $\mathrm{pH}$ value) is considered as one of the most important parameters that influence the adsorption behavior of pollutants ions from wastewater. It influence the solubility of the metal ions in the solution, replaces some of the positive ions found in the active sites and affects the degree of ionization of the adsorbate during the reaction [34].
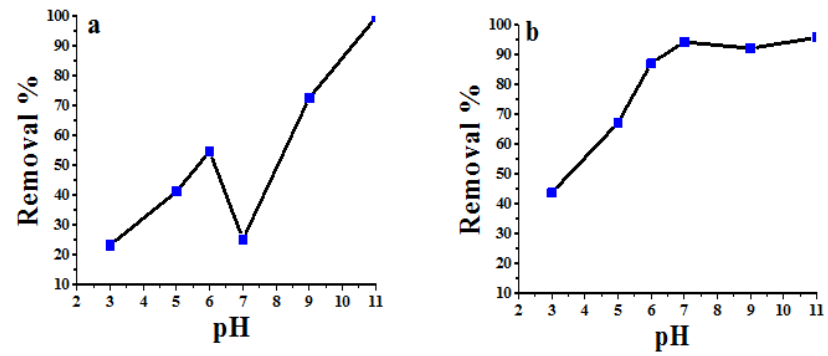

Figure 6. Graphical representation which shows the effect of $\mathrm{pH}$ values on the adsorption of (a) $\mathrm{Cd} @ \mathrm{SnO}_{2}$ (b) $\mathrm{Pb} @ \mathrm{SnO}_{2}$. at adsorbent weight=0.1 g, 25 ppm initial concentration for both, contact time 30 mint for both, at room temperature.

Figure 6-a Show removal of $\mathrm{Cd}$ ions by $\mathrm{SnO}_{2}$ nanoparticles at the initial $\mathrm{pH}$ on the sorption in range of (3-11). The metal removal from solution at $\mathrm{pH}$ beyond $8 \mathrm{did}$ not provide any accurate results, where the pollutants ions are precipitated as hydroxides. Therefore, the removal curve increased due to there was not $\mathrm{Cd}$ ions to be removed. By other words, the solution appears to be clear because of the metal precipitation [35]. Figure 6 shows the adsorption behavior of $\mathrm{Cd}$ ions by $\mathrm{SnO}_{2}$ nanoparticles upon changing initial solution $\mathrm{pH}$ value. It's clear that the initial solution $\mathrm{pH}$ value has a remarkable effect on the adsorption capacity. Removal of $\mathrm{Cd}$ ions increases gradually in solution with increasing $\mathrm{pH}$ from 3 to 6 . The maximum recorded value was achieved at $\mathrm{pH}$ of 6 . So, it was considered as better condition. At lower $\mathrm{pH}$ values, the metal ion removal was limited; this is due to the presence of $\mathrm{H}^{+}$ions which compete with the $\mathrm{Cd}$ ions for the adsorption sites.

Figure 6-b Show removal $\mathrm{Pb}$ ions by $\mathrm{SnO}_{2}$ nanoparticles at 
$\mathrm{pH}$ range (3-11). The metal removal from solution at $\mathrm{pH}$ beyond 8 did not provide any accurate results, where the pollutants ions are precipitated as hydroxides. Therefore, the removal curve increased due to there was not Lead ions to be removed. By other words, the solution appears to be clear because of the metal precipitation [35]. Figure 6 shows the adsorption behavior of $\mathrm{Pd}$ ions by $\mathrm{SnO}_{2}$ nanoparticles upon changing initial solution $\mathrm{pH}$ value. It's clear that the initial solution $\mathrm{pH}$ value has a remarkable effect on the adsorption capacity. Removal of $\mathrm{Pd}$ ions increases gradually with increasing solution $\mathrm{pH}$ from 3 to 7 . The maximum recorded value was reached at $\mathrm{pH}$ of 7 . So, it was considered as optimum condition. At lower $\mathrm{pH}$ values, the metal ion removal was limited; this is due to the presence of $\mathrm{H}^{+}$ions which compete with the $\mathrm{Pd}$ ions for the adsorption sites.

Table 2 summarized the optimum adsorption conditions for all studied samples. The highest adsorption was recorded for sample $\mathrm{CuO}$ where removed $99.7 \%$ of Lead ions from wastewater. The optimum adsorption conditions were Contact time 30 mint and PH 7.

Table 2. The optimum adsorption conditions.

\begin{tabular}{lllll}
\hline Sample code & Adsorbent & Pollutant & Highest adsorption R\% & Adsorption conditions \\
\hline $\mathrm{Cd} @ \mathrm{CuO}$ & $\mathrm{CuO} \mathrm{NP}$ & $\mathrm{Cd}$ & $57.14 \%$ & $\mathrm{Contact}$ time 30 mint and PH 6 \\
$\mathrm{Pb} @ \mathrm{CuO}$ & $\mathrm{CuO} \mathrm{NP}$ & $\mathrm{Pb}$ & $99.7 \%$ & $\mathrm{Contact}$ time 30 mint and PH 7 \\
$\mathrm{Cd} @ \mathrm{SnO}_{2}$ & $\mathrm{SnO} \mathrm{NP}_{2}$ & $\mathrm{Cd}$ & $54.75 \%$ & $\mathrm{Contact}$ time 30 mint and PH 6 \\
$\mathrm{Pb} @ \mathrm{SnO}_{2}$ & $\mathrm{SnO}_{2} \mathrm{NP}$ & $\mathrm{Pb}$ & $94.34 \%$ & $\mathrm{Contact} \mathrm{time} \mathrm{30} \mathrm{mint} \mathrm{and} \mathrm{PH} \mathrm{7}$ \\
\hline
\end{tabular}

\section{Conclusion}

Facile and economic perception method had been used to precipitate crystalline Copper and Tin oxide nanoparticles where $\mathrm{CuO}$ and $\mathrm{SnO}_{2}$ nanoparticles with different morphologies have been synthesized by precipitation and sol gel method respectively using microwave heating technique. The produced $\mathrm{CuO}$ and $\mathrm{SnO}_{2}$ nanoparticles were characterized by XRD and SEM. The XRD patterns and SEM micrographs approve the structure of the prepared pure $\mathrm{CuO}$ and $\mathrm{SnO}_{2}$ nanoparticles.

Nanoparticles supply an efficient mechanism for the adsorption of $\mathrm{Pb}$ and $\mathrm{Cd}$ heavy metals from wastewater. In this research, $\mathrm{CuO}$ and $\mathrm{SnO}_{2}$ nanoparticles have been used as adsorbent in batch adsorption experiments for the removal of lead and cadmium from aqueous solutions.

The adsorption behavior has been tested under various conditions, such as; $\mathrm{pH}$ values, contact time. The obtained results can be summarized as: The highest adsorption for both $\mathrm{Pb}$ and $\mathrm{Cd}$ were recorded after 30 minutes. The $\mathrm{pH}$ experiments showed that the governing factors affecting the adsorption characteristics of all $\mathrm{CuO}$ and $\mathrm{SnO}_{2}$ nanoparticles are competition of the $\mathrm{H}^{+}$ions with metal ions at low $\mathrm{pH}$ values, maximum adsorption at $\mathrm{pH} 7$ for lead and 6 for cadmium. Removal percentage $\%$ of lead and cadmium heavy metals was found to increase, reach a maximum value with increase in contact time and $\mathrm{pH}$ values. These oxide nanoparticles are highly recommended to be applied in water treatment applications.

\section{References}

[1] X. Qu, P. J. J. J. Alvarez, Q. Li, Applications of nanotechnology in water and wastewater treatment, Water Res. 47 (2013) 3931-3946. doi: 10.1016/j.watres.2012.09.058.

[2] M. A. Barakat, New trends in removing heavy metals from industrial wastewater, Arab. J. Chem. 4 (2011) 361-377. doi: 10.1016/j.arabjc.2010.07.019.

[3] T. G. Chuah, A. Jumasiah, I. Azni, S. Katayon, S. Y. Thomas
Choong, Rice husk as a potentially low-cost biosorbent for heavy metal and dye removal: An overview, Desalination. 175 (2005) 305-316. doi: 10.1016/j.desal.2004.10.014.

[4] T. I. Shalaby, M. F. El-Kady, A. E. H. M. Zaki, S. M. El-Kholy, Preparation and application of magnetite nanoparticles immobilized on cellulose acetate nanofibers for lead removal from polluted water, Water Sci. Technol. Water Supply. 17 (2017) 176-187. doi: 10.2166/ws.2016.124.

[5] M. S. Abdullahi, Toxic effects of lead in humans: An overview, Glob. Adv. Res. J. Environ. Sci. Toxicol. 2 (2013) 157-162. http://garj.org/garjest/index.htm.

[6] S. N. A. Abas, M. H. S. Ismail, M. L. Kamal, S. Izhar, Adsorption process of heavy metals by low-cost adsorbent: A review, World Appl. Sci. J. 28 (2013) 1518-1530. doi: 10.5829/idosi.wasj.2013.28.11.1874.

[7] Y. Zhang, X. Duan, Chemical precipitation of heavy metals from wastewater by using the synthetical magnesium hydroxy carbonate, Water Sci. Technol. 81 (2020) 1130-1136. doi: 10.2166/wst.2020.208

[8] U.S. Environmental Protection Agency, Wastewater Technology Fact Sheet Chemical Precipitation - EPA Document \# EPA 832-F-00-018, Environ. Prot. Agency. (2000) $1-7$.

[9] A. Bashir, L. A. Malik, S. Ahad, T. Manzoor, M. A. Bhat, G. N. Dar, A. H. Pandith, Removal of heavy metal ions from aqueous system by ion-exchange and biosorption methods, Environ. Chem. Lett. 17 (2019) 729-754. doi: 10.1007/s10311-018-00828-y.

[10] T. Bakalár, M. Búgel, L. Gajdošová, Heavy metal removal using reverse osmosis, Acta Montan. Slovaca. 14 (2009) 250253.

[11] E. T. Musapatika, M. S. Onyango, O. Aoyi, Cobalt(II) removal from synthetic wastewater by adsorption on South African coal fly ash, S. Afr. J. Sci. 106 (2010) 1-7. doi: 10.4102/sajs.v106i9/10.167.

[12] M. MOUSTAFA, S. ALAMRI, M. ELNOUBY, T. TAHA, M. A. ABU-SAIED, A. SHATI, M. AL-KAHTANI, S. ALRUMMAN, Hydrothermal preparation of $\mathrm{TiO}_{2}-\mathrm{Ag}$ nanoparticles and its antimicrobial performance against human pathogenic microbial cells in water, Biocell. 42 (2019) 93-97. doi: 10.32604/biocell.2018.07014. 
[13] R. Bhateria, R. Singh, A review on nanotechnological application of magnetic iron oxides for heavy metal removal, J. Water Process Eng. 31 (2019) 100845. doi: 10.1016/j.jwpe.2019.100845.

[14] Y. J. Tu, T. S. Chan, H. W. Tu, S. L. Wang, C. F. You, C. K. Chang, Rapid and efficient removal/recovery of molybdenum onto $\mathrm{ZnFe} 2 \mathrm{O} 4$ nanoparticles, Chemosphere. 148 (2016) 452 458. doi: 10.1016/j.chemosphere.2016.01.054.

[15] S. L. Iconaru, R. Guégan, C. L. Popa, M. Motelica-Heino, C. S. Ciobanu, D. Predoi, Magnetite (Fe3O4) nanoparticles as adsorbents for As and Cu removal, Appl. Clay Sci. 134 (2016) 128-135. doi: 10.1016/j.clay.2016.08.019.

[16] G. G. Bessegato, T. T. Guaraldo, J. F. de Brito, M. F. Brugnera, M. V. B. Zanoni, Achievements and Trends in Photoelectrocatalysis: from Environmental to Energy Applications, Electrocatalysis. 6 (2015) 415-441. doi: 10.1007/s12678-015-0259-9.

[17] M. Ghulam, T. Hajira, S. Muhammad, A. Nasir, Synthesis and characterization of cupric oxide $(\mathrm{CuO})$ nanoparticles and their application for the removal of dyes, African J. Biotechnol. 12 (2013) 6650-6660. doi: 10.5897/ajb2013.13058.

[18] S. J. Davarpanah, R. Karimian, V. Goodarzi, F. Piri, Synthesis of copper (II) oxide $(\mathrm{CuO})$ nanoparticles and its application as gas sensor, J. Appl. Biotechnol. Reports. 2 (2015) 329-332.

[19] R. Manimaran, K. Palaniradja, N. Alagumurthi, S. Sendhilnathan, J. Hussain, Preparation and characterization of copper oxide nanofluid for heat transfer applications, Appl. Nanosci. 4 (2014) 163-167. doi: 10.1007/s13204-012-0184-7.

[20] K. H. Hassan, E. R. Mahdi, Synthesis and Characterization of Copper, Iron Oxide Nanoparticles used to Remove Lead from Aquous Solution, 04 (2016) 730-738.

[21] W. Zhang, B. Yang, J. Liu, X. Chen, X. Wang, C. Yang, Highly sensitive and low operating temperature $\mathrm{SnO}_{2}$ gas sensor doped by $\mathrm{Cu}$ and $\mathrm{Zn}$ two elements, Sensors Actuators, $\begin{array}{llll}\text { B Chem. } 243 \quad \text { (2017) 982-989. doi: } & \end{array}$ 10.1016/j.snb.2016.12.095.

[22] M. H. Jo, B. R. Koo, H. J. Ahn, Accelerating F-doping in transparent conducting F-doped $\mathrm{SnO}_{2}$ films for electrochromic energy storage devices, Ceram. Int. 46 (2020) 25066-25072. doi: $10.1016 /$ j.ceramint.2020.06.293.

[23] H. Kim, H. Kim, S. Muhammad, J. H. Um, M. S. A. Sher Shah, P. J. Yoo, W. S. Yoon, Catalytic effect of reduced graphene oxide on facilitating reversible conversion reaction in $\mathrm{SnO}_{2}$ for next-generation Li rechargeable batteries, J. Power Sources. 446 (2020) 227321. doi: 10.1016/j.jpowsour.2019.227321.

[24] M. Usman Hameed, S. Ullah Dar, S. Ali, S. Liu, R. Akram, Z. Wu, I. S. Butler, Facile synthesis of low-dimensional $\mathrm{SnO}_{2}$ nanostructures: An investigation of their performance and mechanism of action as anode materials for lithium-ion batteries, Phys. E Low-Dimensional Syst. Nanostructures. 91 (2017) 119-127. doi: 10.1016/j.physe.2017.04.020.
[25] H. Howari, I. B. I. Tomsah, Structural, optical and ellipsometric characteristics of PVD synthesized $\mathrm{SnO}_{2}$ thin films on Pt coated silicon wafers, Optik (Stuttg). 144 (2017) 467-474. doi: 10.1016/j.ijleo.2017.05.098.

[26] R. Alizadeh, R. K. Kazemi, M. R. Rezaei, Ultrafast removal of heavy metals by tin oxide nanowires as new adsorbents in solid-phase extraction technique, Int. J. Environ. Sci. Technol. 15 (2018) 1641-1648. doi: 10.1007/s13762-017-1481-1.

[27] P. Sivakarthik, V. Thangaraj, K. Perumalraj, J. Balaji, Synthesis of co-doped tin oxide nanoparticles for photo catalytic degradation of synthetic organic dyes, Dig. J. Nanomater. Biostructures. 11 (2016) 935-943.

[28] B. Dye, E. M. Elsayed, M. S. Elnouby, M. H. Gouda, N. A. Elessawy, S. M. H. Gouda, N. A. Elessawy, D. M. F. Santos, Effect of the morphology of tungsten oxide embedded in sodium alginate/polyvinylpyrrolidone composite beads on the photocatalytic degradation of methylene blue dye solution, Materials (Basel). 13 (2020). doi: 10.3390/MA13081905.

[29] M. Shaban, M. R. Abukhadra, A. A. P. Khan, B. M. Jibali, Removal of Congo red, methylene blue and $\mathrm{Cr}(\mathrm{VI})$ ions from water using natural serpentine, J. Taiwan Inst. Chem. Eng. 82 (2018) 102-116. doi: 10.1016/j.jtice.2017.10.023.

[30] K. Nithya, P. Yuvasree, N. Neelakandeswari, N. Rajasekaran, K Uthayarani, M. Chitra, S. Sathiesh Kumar, Preparation and characterization of copper oxide nanoparticles, Int. J. ChemTech Res. 6 (2014) 2220-2222. doi: $10.5246 /$ jcps.2020.09.057.

[31] K. Y. Kumar, T. N. V. Raj, S. Archana, S. B. B. Prasad, S. Olivera, H. B. Muralidhara, $\mathrm{SnO}_{2}$ nanoparticles as effective adsorbents for the removal of cadmium and lead from aqueous solution: Adsorption mechanism and kinetic studies, J. Water Process Eng. 13 (2016) 44-52. doi: 10.1016/j.jwpe.2016.07.007.

[32] O. Fadali, T. Farrag, A. Abdelbasier, Pesticides Removal from wastewater by Electrocoagulation Technique Using Stainless Steel (Ss-Ss) Plate Electrodes., Bull. Fac. Eng. Mansoura Univ. 40 (2020) 1-10. doi: 10.21608/bfemu.2020.96410.

[33] D. Jiang, Y. Yang, C. Huang, M. Huang, J. Chen, T. Rao, X. Ran, Removal of the heavy metal ion nickel (II) via an adsorption method using flower globular magnesium hydroxide, J. Hazard. Mater. 373 (2019) 131-140. doi: 10.1016/j.jhazmat.2019.01.096.

[34] J. Chen, N. Wang, Y. Liu, J. Zhu, J. Feng, W. Yan, Synergetic effect in a self-doping polyaniline $/ \mathrm{TiO}_{2}$ composite for selective adsorption of heavy metal ions, Synth. Met. 245 (2018) 32-41. doi: 10.1016/j.synthmet.2018.08.006.

[35] M. Sharma, J. Singh, S. Hazra, S. Basu, Adsorption of heavy metal ions by mesoporous $\mathrm{ZnO}$ and $\mathrm{TiO}_{2} @ \mathrm{ZnO}$ monoliths: Adsorption and kinetic studies, Microchem. J. 145 (2019) 105-112. doi: 10.1016/j.microc.2018.10.026. 